\title{
Roflumilast is effective in reducing COPD related exacerbations and improving CAT score
}

\author{
Biagio Polla ${ }^{*}$
}

ABSTRACT: Roflumilast is effective in reducing COPD related exacerbations and improving $C A T$ score. B. Polla.

We present a case of a 85-year-old man who suffered from several chronic obstructive pulmonary disease (COPD) related exacerbations and hospitalizations. Traditional therapy, which also included intramuscular steroid therapy, did not help and caused several drug related adverse events. After yet another exacerbation followed by hospitalization at the intensive care unit, it was decided to start roflumilast treatment. In the year after beginning treatment, the patient did not experience any more exacerbations and his lung function also improved, as recorded by the COPD assessment test (CAT) score and improved forced expiratory volume in the first second $\left(\mathrm{FEV}_{1}\right)$ value. In this patient roflumilast seems to be effective in reducing exacerbations, an important goal to be achieved in COPD patients. Monaldi Arch Chest Dis 2013; 79: 3-4, Suppl., 41-44.

Keywords: Roflumilast, COPD, Case report, Exacerbations, Steroid therapy.

1 Respiratory Physiopathology and Anti-Smoke Center, "SS. Antonio e Biagio e Cesare Arrigo" Hospital, Alessandria, Italy.

Correspondence: Biagio Polla, MD, Centro di Fisiopatologia Respiratoria - Centro Antifumo, Ospedale “SS. Antonio e Biagio e Cesare Arrigo”, Via Venezia 16, 15100 Alessandria, Italy; e-mail: bpolla@ospedale.al.it

\section{Case Report}

An 85-year-old male patient, former smoker (60 pack-years) and railway man, came to our clinic for the first time in 2005. Post bronchodilator (BD) forced expiratory volume in the first second $\left(\mathrm{FEV}_{1}\right)$ was 0.89 $\mathrm{L}$ (36\% of predicted), residual volume (RV) was $172 \%$ of predicted, forced vital capacity (FVC) was $2.33 \mathrm{~L}$ (70\% of predicted) and $\mathrm{FEV}_{1} / \mathrm{FVC}$ was 0.38 . He was diagnosed with severe chronic obstructive pulmonary disease (COPD). At the time of the first visit, the patient was under daily treatment with tiotropium $18 \mu \mathrm{g} /$ day, salmeterol $100 \mu \mathrm{g} /$ day, fluticasone $1000 \mu \mathrm{g} / \mathrm{day}$ and theophylline

This work originated from the Respiratory Physiopathology and Anti-Smoke Center, "SS. Antonio e Biagio e Cesare Arrigo" Hospital, Via Venezia 16, 15100 Alessandria, Italy, and has been supported by a grant from Takeda Italia SpA.

* The author received a consultancy fee by Takeda Italia SpA for clinical data collection.

Editorial assistance was provided by Selene Mogavero, PhD and Colin G Egan, PhD (Primula Multimedia SrL) and was sponsored by Takeda Italia SpA. 
$400 \mathrm{mg} /$ day. Medical history did not reveal any other significant morbidity. The patient had severe dyspnea at the slightest exercise, which greatly reduced his normal activities (modified medical research council scale of 4). For this reason he was already undergoing therapy with intramuscular betamethasone $4 \mathrm{mg} /$ week for approximately the past two years. This steroid therapy resulted, as time passed, in severe side effects such as osteoporosis, skin atrophy and increased susceptibility to infections. In later years the patient also experienced 3-4 exacerbations/year with further decrease in physical activity and increase in dyspnea and sputum production, which sometimes was purulent. In December 2011 the patient experienced yet another severe exacerbation requiring hospitalization at the respiratory intensive care unit and he was diagnosed with hypoxemic and hypercapnic respiratory failure in COPD. He also required non-invasive ventilation for a few days. After this episode, it was decided to start therapy with roflumilast, eliminating theophylline and keeping the rest of therapy unchanged. The COPD assessment test (CAT) score at the beginning of therapy with roflumilast was 35. After about 1 year of therapy, CAT score was 30, without significant side effects. Moreover, there were no exacerbations worth noting and the consumption of intramuscular steroid therapy was virtually zero with positive changes also seen in $\mathrm{FEV}_{1}$ values ( $41 \%$ of predicted, Global Initiative for Chronic Obstructive Lung Disease - GOLD - stage D).

\section{Discussion}

Several studies have focused their attention on the impact of acute exacerbations on the natural history of COPD, confirming that exacerbations have negative consequences, in the short and long-term, on the quality of life (QoL) of the patient [1-3]. In the short term, exacerbations result in a modest, but still measurable, reduction in lung function which is susceptible to further worsening with repeated exacerbations. Since the risk of exacerbations is determined by past episodes, patients with frequent exacerbations have been suggested to compose a distinct phenotypic group [2]. This is even clearer if the patient has a history of chronic cough and sputum production, since those are associated with the development of severe exacerbations requiring hospitalization [1]. The ECLIPSE study - involving over 2,000 patients with moderate to very severe COPD - confirmed that the best predictor for exacerbations is given by a history of repeated exacerbations, emphasizing the validity of this observation at all stages of COPD [2]. It is also known that mortality risk increases together with the frequency of severe exacerbations. The increased mortality risk is observed in those patients with 3 or more exacerbations, particularly if requiring hospitalization [3].

The CAT test is a useful tool to assess the health status of the patient. It is a validated, short, simple and complete test, with good discriminating ability, which has been developed to measure the health status of patients with COPD in clinical practice [4]. Research is still ongoing to understand what the minimum significant difference is between CAT scores, however, a strong correlation between the CAT and the St George's respiratory questionnaire has been demonstrated and it is suggested that a difference of 2 or more points in the CAT score is clinically significant for the patient's health status [5]. Moreover, the first study performed on CAT score showed that in patients with moderate/severe exacerbations the score of the questionnaire was approximately 5 units higher than in patients with stable COPD [4].

As noted in GOLD guidelines, COPD shows an abnormal inflammatory response of the lungs to noxious particles or gases, primarily caused by cigarette smoking [6]. Corticosteroids are often used to decrease this inflammation in COPD patients. Unfor- 
tunately, it is not possible to separate the anti-inflammatory effects of corticosteroids from their metabolic effects, so, when a corticosteroid is prescribed, protective measures should be adopted to minimize their side effects. Clearly, the chance of significant side effects increases with the dose and the duration of corticosteroid treatment. Therefore, they have to be administered at the lowest possible dose required to control the disease [7].

In the case report presented, after one year of treatment with roflumilast, the patient showed a marked improvement, from 34 moderate-severe exacerbations per year to no exacerbations during the 12-month-treatment with roflumilast. The patient also showed an improvement of his health status based on his CAT score, which decreased from 35 to 30 , with a very positive impact on patient's QoL.

Finally it should be noted that prior to initiating therapy with roflumilast the patient constantly needed intramuscular corticosteroids which led to the onset of severe side effects such as osteoporosis, skin atrophy and increased susceptibility to infections. Following treatment with roflumilast the patient no longer needed therapy with corticosteroids which resulted in a marked improvement of his overall clinical conditions.

\section{Riassunto}

Presentiamo il caso clinico di un uomo di 85 anni che soffriva di molte riacutizzazioni di broncopneumopatia cronica ostruttiva (BPCO) ed ospedalizzazioni correlate. La terapia tradizionale, che comprendeva anche terapia steroidea per via intramuscolare, non funzionava, causando tra l'altro diversi eventi avversi correlati al farmaco. Dopo l'ennesimo aggravamento seguito da ricovero presso il reparto di terapia intensiva, si decideva di iniziare il trattamento con roflumilast. Nell' anno a seguire, il paziente non ha più subito esacerbazioni ed è migliorata la sua funzionalità polmonare, evidenziata dal punteggio del "COPD assessment test" (CAT) e dal miglioramento dei valori di volume espiratorio forzato nel primo secondo $\left(F E V_{l}\right)$. In questo paziente roflumilast sembra essere efficace nel ridurre le riacutizzazioni, un obiettivo importante da raggiungere nei pazienti con BPCO.

Parole chiave: Roflumilast, BPCO, Caso clinico, Riacutizzazioni, Terapia steroidea.

\section{References}

1. Burgel P-R, Nesme-Meyer P, Chanez $\mathrm{P}$, et al. Cough and sputum production are associated with frequent exacerbations and hospitalizations in COPD subjects. Chest 2009; 135: 975-982.

2. Hurst JR, Vestbo J, Anzueto A et al. Susceptibility to exacerbation in chronic obstructive pulmonary disease. N Engl J Med 2010; 363: 11281138 .

3. Soler-Cataluña JJ, Martínez-García MA, Román Sánchez P, et al. Severe acute exacerbations and mortality in patients with chronic obstructive pulmonary disease. Thorax 2005; 60: 925-931.

4. Jones PW, Harding G, Berry P, et al. Development and first validation of the COPD Assessment Test. Eur Respir J 2009; 34: 648-654.

5. Jones PW, Brusselle G, Dal Negro RW, et al. Properties of the COPD assessment test in a cross-sectional European study. Eur Respir $J$ 2011; 38: 29-35.

6. Global Initiative for Chronic Obstructive Lung Disease (GOLD). Global Strategy for the Diagnosis, Management and Prevention of COPD. 2013. Available at www.goldcopd.org.

7. Stanbury RM, Graham EM. Systemic corticosteroid therapy - side effects and their management. Br J Ophthalmol 1998; 82: 704-708. 


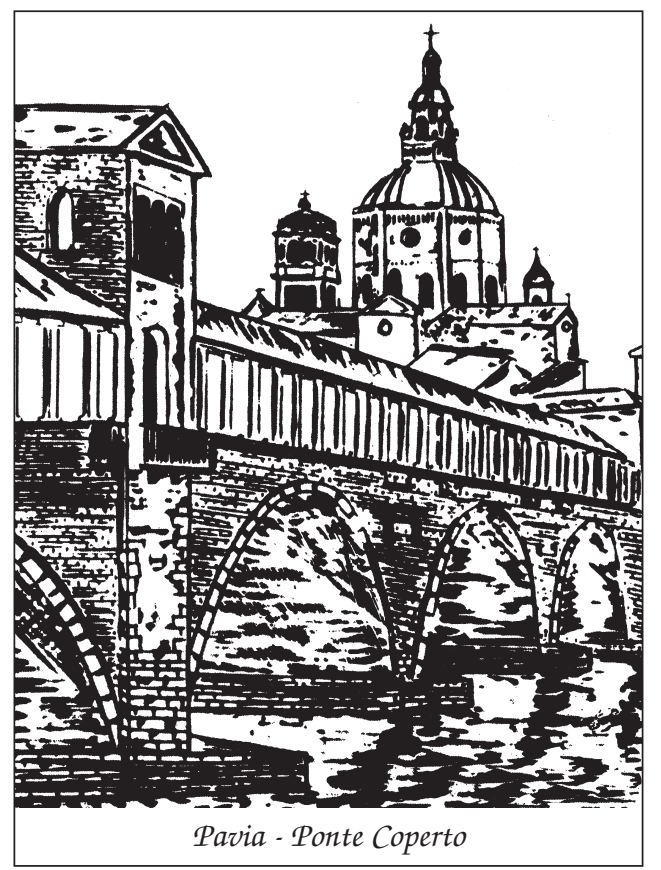

